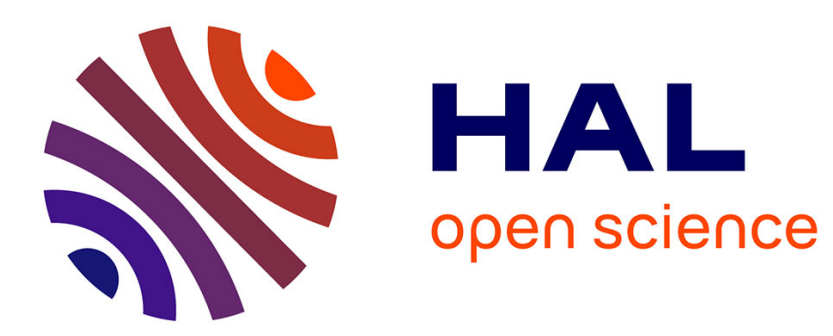

\title{
Stability of Pseudo-Funicular Elastic Grid Shells
}

Romain Mesnil, John Ochsendorf, Cyril Douthe

\section{To cite this version:}

Romain Mesnil, John Ochsendorf, Cyril Douthe. Stability of Pseudo-Funicular Elastic Grid Shells. International Journal of Space Structures, 2015, 30 (1), pp.27-37. 10.1260/0266-3511.30.1.27 . hal01200528

\section{HAL Id: hal-01200528 \\ https://hal.science/hal-01200528}

Submitted on 5 Oct 2015

HAL is a multi-disciplinary open access archive for the deposit and dissemination of scientific research documents, whether they are published or not. The documents may come from teaching and research institutions in France or abroad, or from public or private research centers.
L'archive ouverte pluridisciplinaire HAL, est destinée au dépôt et à la diffusion de documents scientifiques de niveau recherche, publiés ou non, émanant des établissements d'enseignement et de recherche français ou étrangers, des laboratoires publics ou privés. 


\title{
Stability of Pseudo-Funicular Elastic Grid Shells
}

\section{Romain Mesnil1 ${ }^{1}$, John Ochsendorf ${ }^{1}$ and Cyril Douthe ${ }^{3}$}

\author{
${ }^{1}$ Massachusetts Institute of Technology \\ ${ }^{2}$ Université Paris-Est, Laboratoire Navier (UMR 8205) \\ ${ }^{3}$ Université Paris-Est, IFSTTAR
}

(Submitted on 19/02/2015, Reception of revised paper 09/04/2015, Accepted on 13/04/2015)

\begin{abstract}
The paper presents some results on the influence of the pre-stress induced by the erection method of elastic grid shells on their buckling capacity. It starts with the numerical methods and their validation with the study of a prebuckled arch. Then, a form-finding scheme using low-speed dynamics is used to generate automatically a family of elastic grid shells, and their buckling capacity is compared to the one of grid shells with the exact same geometry, but without any pre-stress. The paper demonstrates finally that the pre-stress decreases by a few percent the buckling capacity of elastic grid shells.
\end{abstract}

Key Words: elastic grid shell, lightweight structures, linear buckling analysis, active bending

\section{INTRODUCTION}

The word grid shell is commonly employed to describe a structure with double curvature and built out of discrete members. Two typologies of grid shells exist. The first one is made of straight members assembled on a desired surface, and requires a consequent amount of work to manage the complexity of the connections. The use of $\mathrm{CNC}$ and digital tools has allowed the multiplication of such structures in the past decade [1]. The second one is the result of the elastic deformation of an initially flat grid with no in-plane shear stiffness, and thus resolves the geometric complexity of the connections. The bracing of the final shape provides a sufficient stiffness and a shell behavior. This construction principle has only been used a few times: for the Bundesgartenschau in Mannheim [2], for the Downland Museum [3], or for an experimental grid shell in GFRP [4], and more recently, a temporary cathedral using GFRP [5]. Since the mounting sequence is based on the elastic bending deformation of the members, these structures are also known as "elastic grid shells", in opposition to "rigid grid shells", which are built from individual rigid members.

The erection process of elastic grid shells induces thus that the double curved shape corresponds to a pre-stressed state of the structure which is expected to decrease its performance. It has already been pointed out that, much like continuous shells, grid shells are particularly sensitive to buckling [6]. It is known that increasing the curvature of an arch or a shell increases its buckling capacity [7]. However, increasing the curvature of the elements in an elastic grid shell also means increasing the initial bending moment and compression forces in the structure, which has a negative effect on the buckling load. No simple calculation allows the comparison of these competing effects of the deformation of an initial geometry.

Moreover, the analysis of grid shells reveals that they exhibit a wide variety of buckling modes [8], which might be influenced by the pre-stress. The coupling between internal stress and geometrical stiffness of elastic grid shells has therefore to be investigated and understood both qualitatively and quantitatively. In the present article, it will be focused on two questions. Does the pre-stress affect the buckling mode shapes? How does the pre-stress affect quantitatively the bearing capacity of elastic grid shells?

The preferred tool for this kind of problems is a parametric numerical study. The precise methodology

\footnotetext{
*Corresponding author e-mail: romain.mesnil@enpc.fr
} 
is presented in the second section. The Finite Element Method is used for both form-finding and buckling analysis, this choice is validated with a comparison to existing literature. In the third section, results on the buckling of the Elastica used as an arch are presented. A simple analytical formula illustrates the fact that the buckling capacity of pre-stressed arches is mainly governed by initial axial forces. The buckling of pseudo-funicular elastic grid shells, which is the main topic of this paper, is investigated in Section 4. In this section, the choice of the parameters is discussed and compared to real values of existing projects. The parametric study shows that the buckling capacity of pseudo-funicular elastic grid shells is slightly reduced by the pre-stress. A brief conclusion sums up the main contributions of this paper.

\section{METHODOLOGY}

Numerical methods are the preferred tool to quantify the stability of grid shells [6], [8]. This work puts emphasis on the use of finite element analysis, and more specifically of the linearized buckling analysis with the software ADINA. The approach chosen is to conduct a parametric study for a unique grid topology (an initially flat circular grid) with different levels of pre-stress and grid density. This choice of geometry is natural, because the dome typology is a common feature of architecture. Moreover, it has much symmetry that decreases the number of parameters to take into account. The problem is expressed in a dimensionless form, and the non-dimensional buckling capacity of the pre-stressed structure and unstressed structure are compared. The values of the parameters are chosen after study of existing designs in order to have reasonable values.
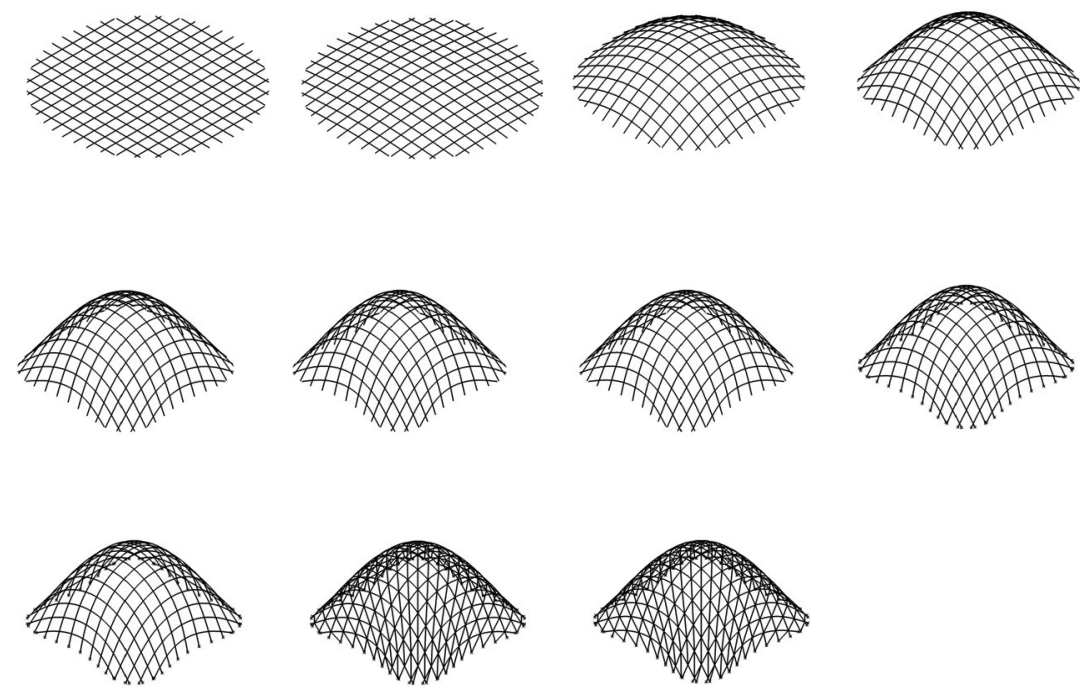

Figure 1. Different steps of the form-finding of an elastic grid shell.

\subsection{Procedure employed} elastic grid shells. as follows, and illustrated in Figure 1: slide freely in the initial plane. the calculation.

Despite the increase of computational power, a complete incremental analysis of a structure up to collapse and beyond remains relatively time-consuming and expensive. One of the most delicate aspects of the analysis of grid shells is the sensitivity to imperfections, which are not well documented for elastic grid shells except in [23]. A common procedure prescribed by the former German codes for steel structures and in the appendix of the Eurocode is to apply an imperfection proportional to the buckling shape and to perform fully nonlinear analysis [10-11]. This procedure, which is the most reliable, requires a linear buckling analysis in the first place. This last procedure remains thus an appealing procedure in practical cases, especially because it is considerably less computationally intensive. In the following of [9] and [12], this study focuses thus on the linearized buckling analysis of

The procedure of the numerical simulations and the study of the influence of the pre-stress is summarized

a The grid is initially flat. The 2-node Hermitian beam elements are connected with links (Master/Slave nodes) and the ends of the grid can

b A vertical line load is applied to the members, and the deformed shape of the grid is calculated using the static solver of ADINA and the Slow Dynamics option, which is required to stabilize

c The vertical load is taken away and pin supports are added at the boundary. The diagonal bracing is then added to the relaxed structure. Since the 
bracing is added on the relaxed structure, no additional forces are induced after the relaxation.

d A load is applied and the linearized buckling calculation is performed with ADINA.

e The step d. is repeated for a structure with the same geometry, but without any pre-stress.

The central feature of this procedure is that it combines form-finding and buckling analysis in the same computing environment, in the followings of works that have used dynamic relaxation [4] or explicit dynamics [13].

\subsection{Bracing system}

The bracing step is key to the structural efficiency of the grid shell. Before it is added, the grid behaves as a network of connected arches, but the structure lacks in-plane shear stiffness, only the braced structure can be compared to a discretized shell [25]. Three technologies were used in historical examples. The first one, used in the Mannheim Multihalle, is a cross bracing with cables of one out of five cells of the grid [2]. Because the effectiveness of this solution relies on the pre-stress in the cables, and because materials used for elastic grid shells are subject to creep, this technical solution requires on-site adjustments after the construction. This led to the introduction of bracing systems based on a third layer of elastically deformed members and connected to the form-found grid $[3,4,13,14]$. More recently, timber grid shells with rigid bracing were built [22].

A first study has been conducted in [23] to investigate the influence of prestress. It focused on the local buckling of spheric elastic grid shells braced with a third prestressed layer and compared their bearing capacity to that of similar gridshells without prestress. It demonstrated that the influence of prestress is very low (less than 3\%) and that the prestress distribution being very complex, it does not always reduce the capacity. Considering the specificity of the spherical form and the incertitude of the prestress field induced by the bracing, it was decided here to focus on pseudo-funicular shapes (with more homogeneous prestress) braced with rods. Two reasons justify this choice. Firstly, this bracing system has been used in recent projects and is a reasonable alternative to more conventional bracing techniques. Secondly, and unlike a bracing system with a third pre-stressed layer, adding rigid rods after the relaxation of the structure does not affect the distribution of forces and moments due to pre-stress in the grid. This guarantees a more straightforward interpretation of the results in terms of prestress of the grid.

The stiffness of the members composing the third layer influences the whole behavior of the shell, it is therefore important to estimate realistic values based on existing projects. Because most of the rigid diagonal bracing use a third curved layer, it is necessary to quantify the loss of stiffness due to the curvature. This has been done in [19] by studying the actual curvature of bracing members in recent grid shells and by estimating the stiffness of the bracing rods along the chords as the horizontal stiffness of equivalent circular arches. This study has shown that, in most cases, setting the stiffness of the rods to $1 \%$ of the axial stiffness of the grid members was a conservative but realistic choice. This value is thus adopted in the present work.

\section{3. $2 D$ Validation of the linearized buckling procedure}

No existing literature allows a validation of the linear buckling analysis on a 3D structure. For that reason, the validation of this procedure has been restrained to a 2D case, and more specifically the example of a prebuckled arch. The interest of this example lays in the fact that several results of experiments and of previous nonlinear calculations are available $[16,17]$. The problem and its notations are shown in Fig. 2. The values of interest are the critical uniform line load for buckling $p_{c r}$, the initial length $L$, the final span $L$, the height of the $\operatorname{arch} h$, the bending stiffness $E I$ and the horizontal reaction force $Q$.

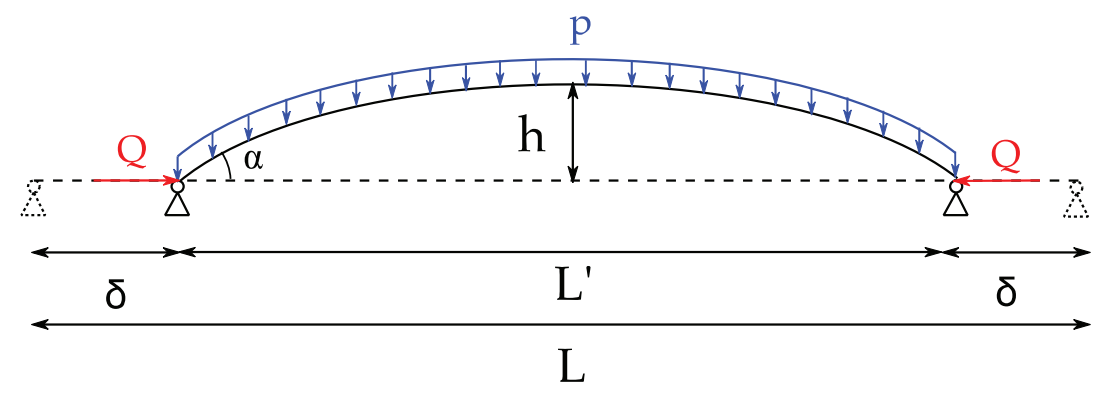

Figure 2. Buckling capacity of a pre-buckled arch. 
Table 1. Comparison of the buckling load for $\frac{h}{L^{\prime}}=0.25$

\begin{tabular}{lccc}
\hline Quantity & Literature [16] & $\begin{array}{c}\text { ADINA } \\
\text { (this work) }\end{array}$ & Error [\%] \\
\hline$\frac{p_{c r} L^{3}}{E I}$ rigid arch & 69.5 & 67.8 & -1.2 \\
$\frac{p_{c r} L^{3}}{E I}$ pre-stressed arch & & & \\
\hline
\end{tabular}

The procedure presented in the Section 2.1 has been adapted to a pre-buckled arch. The buckling capacity of the pre-stressed and the equivalent rigid arch for the case where the parameter $h / L^{\prime}$ is equal to 0.25 is shown in Table 1. The results of the linearized buckling analysis are in accordance with the previous work [16], which validates the method of analysis proposed.

\section{STABILITY OF PRE-BUCKLED ARCHES}

\subsection{Description of the problem}

The proposed methodology being validated, it has been applied on pre-buckled beams used as arches for a broader range of values of the parameters. The principle of construction of non-dimensional parameters for the buckling problem is recalled briefly below.

Because all the geometrical parameters $L, L^{\prime}$ and $h$ can be related together by a curve known as Elastica, knowing two of these values is enough to describe the whole structure. The horizontal reaction force can also be determined if the geometry and the load are known. Therefore, the number of parameters describing the structure is reduced to four parameters, for example: $L$, $h, E I$ and $p_{c r}$. In this example, a Young Modulus of $25 \mathrm{GPa}$, a circular hollow section with an external diameter of $42 \mathrm{~mm}$ and a thickness of $3 \mathrm{~mm}$ with a length of $15 \mathrm{~m}$ have been chosen. This high slenderness is necessary to obtain reasonable stress in the structure. It is comparable to the laths of existing elastic grid shells. A dimensional analysis shows that two non-dimensional parameters can be used to described the problem, in order to remain consistent with the literature, the parameters $\Pi_{1}$ and $\Pi_{2}$ are introduced in equations (1) and (2):

$$
\begin{gathered}
\Pi_{1}=\frac{p_{c r} L^{3}}{E I} \\
\Pi_{2}=\frac{h}{L^{\prime}}
\end{gathered}
$$

In total, 18 values of $\Pi_{2}$, from $5 \%$ to $50 \%$ have been studied. This covers the practical range of application of arches and provides more data than the previous literature [16, 17].

\subsection{Results}

It appears that the buckling modes of the structure are not affected by the pre-stress. In all cases, the first mode is a non-symmetrical in-plane mode (shown in Fig. 3), both for the pre-stressed and rigid arches. This is in accordance with the analytical solutions derived for circular arches by Timoshenko [7] and is directly linked with the high slenderness (low bending rigidity) of the tested arches.

The non-dimensional buckling load is plotted against the inverse of $\Pi_{2}$ in Fig. 4. It appears that the pre-stressed arch has a decreased buckling capacity, which was expected given the fact that the compression force is higher in the pre-stressed arch. However, the critical load increases with the curvature: the negative effect of the pre-stress does not overcome the benefit of the stiffness induced by the form.

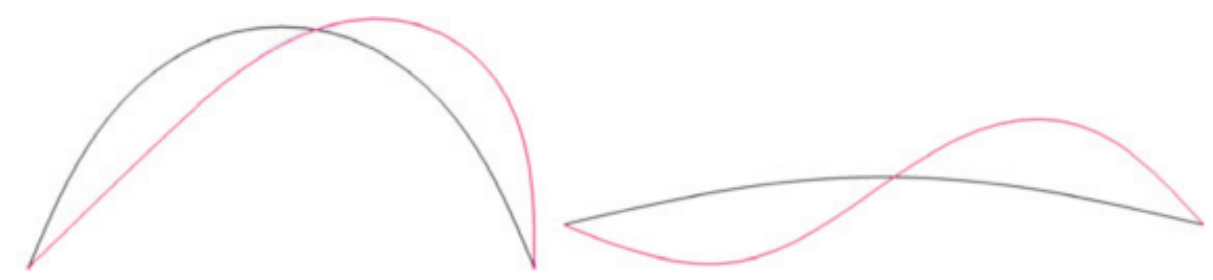

Figure 3. Buckling modes of pre-buckled arches with different rise-over-span ratios (deformed shape in red). 


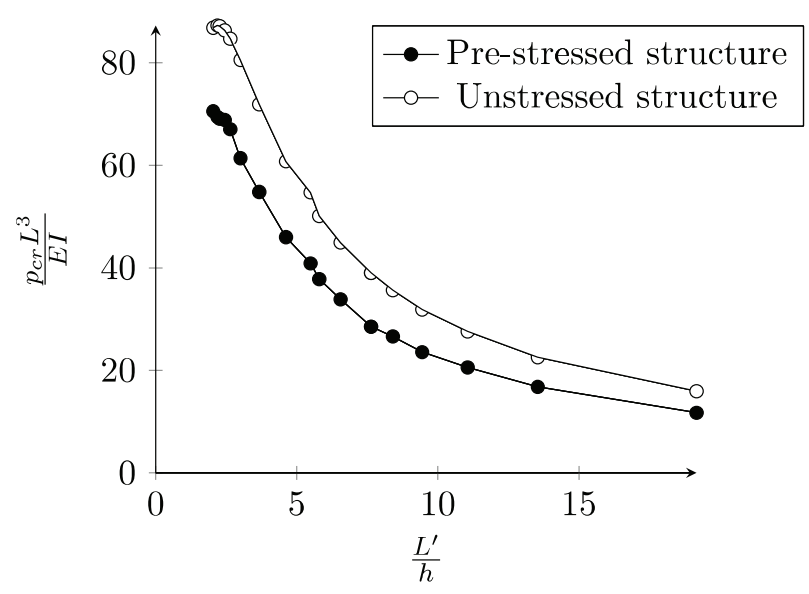

Figure 4. Non-dimensional critical line load of the Elastica: ADINA.

The results of the analysis in the case of the pre-stressed structures were compared with experimental results from [13], as seen in Fig. 5. The correlation between experimental data and finite element analysis is very good and validates the method on a bigger set of data.

\subsection{Discussion: influence of the pre-stress} In order to quantify more precisely the influence of the pre-stress on the stability of pre-buckled arches, the ratio $r$ of the critical load of the pre-stressed and rigid arches has been plotted in Fig. 6. An approximate value of this ratio based on experimental data has been proposed in [18], and is recalled in equation (3).

$$
\frac{p_{c r, \text { pre-stressed }}}{p_{c r, \text { rigid }}}=75 \%
$$

It has been noticed that an interesting relation can be found if this ratio is expressed as a function of the ratio $\frac{\delta}{L}$, where $\delta$ is the support motion, as seen in Fig. 2 .

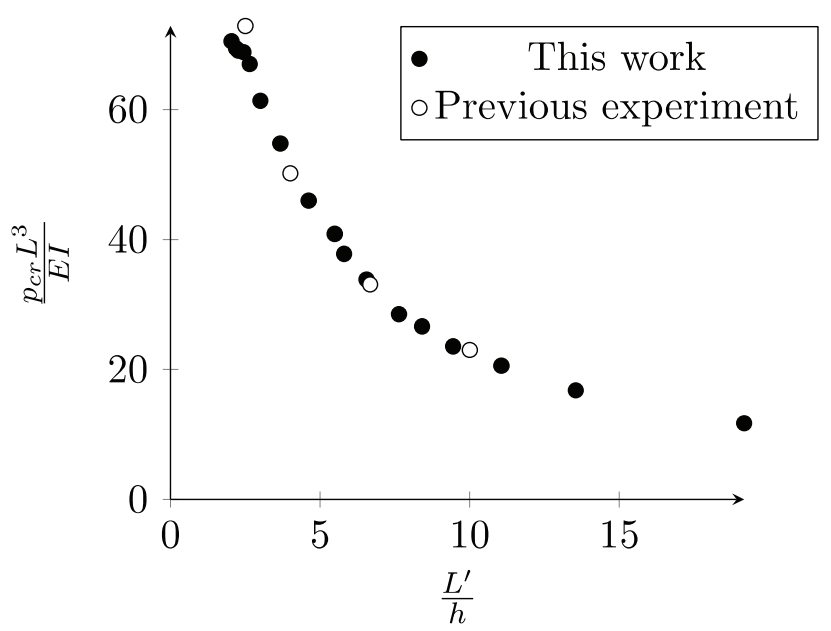

Figure 5. Comparison of the critical line load of a pre-buckled arch: ADINA and [18].

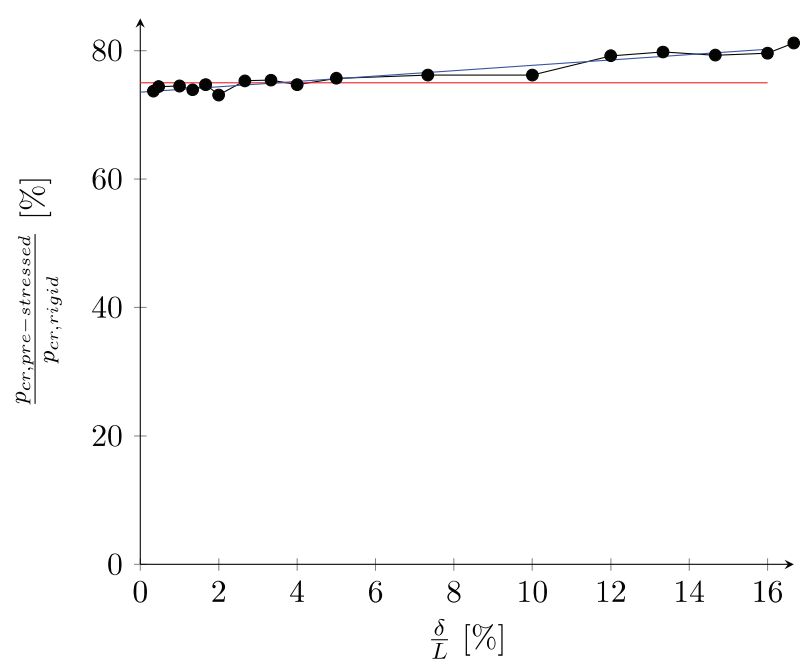

Figure 6. Ratio of the critical load for the pre-stressed and rigid arches: (red: previous approximation [17]; blue: linear regression of the results).

A linear regression on the data obtained from the buckling analysis in ADINA gives, with a correlation of $\mathrm{R}^{2}=0.926$ :

$$
\frac{p_{c r, p r e-s t r e s s e d}}{p_{c r, \text { rigid }}}=0.42 \frac{\delta}{L}+0.74
$$

This approximation is close to the one proposed by Thompson [16], which remains valid for a large spectrum of values of $\delta / L$, as seen in Fig. 6. The value of $75 \%$ can be explained by a simple calculation. Analytical results for the critical axial force in a circular arch can be derived from the critical pressure calculated by Timoshenko [7]. The limit of the axial force at the crown for very shallow arches (when $\alpha \rightarrow 0$ ) is given by equation (5).

$$
N_{c r, \text { crown }}=\frac{4 E I \pi^{2}}{L^{2}}
$$

The theoretical value of the buckling load of a shallow pre-stressed arch is found by noticing that the curvature, and thus the moment induced by the prestress are negligible when $\alpha \rightarrow 0$. Therefore, only the initial axial force $F$ governs the buckling load of a shallow pre-buckled arch. It is noticed that the limit of this force when $\alpha \rightarrow 0$ is given by:

$$
F_{0}=\frac{E I \pi^{2}}{L^{2}}
$$

The theoretical value of the ratio $r$ for shallow arches is given by equation (7) and is in accordance with the value proposed by Thompson.

$$
r=1-\frac{F_{0}}{N_{c r, \text { crown }}}=1-0.25=0.75
$$


The parametric study conducted in this work shows that the ratio $r$ increases with the pre-stress. This can be explained by a more detailed analysis of the internal forces in the arch. The previous analysis has illustrated that the initial axial force largely governs the reduction of the bearing capacity of the arch. During the postbuckling of the beam, the axial force at the crown only varies of $30 \%$ when the angle $\alpha$ described in Fig. 2 varies between $0^{\circ}$ and $90^{\circ}$ [7]. On the same hand, the geometrical stiffness and the buckling capacity of an unstressed arch increase by orders of magnitude, as seen in Fig. 4. Therefore, the relative difference between the buckling loads of pre-stressed and unstressed structures decreases as the pre-stress increases.

So, The methodology employed in this paper allows the generation of accurate data that are in accordance with experimental results. The analysis of the data generated in this work illustrates the fact that prestress decreases the linear buckling load of an Elastica-type arch, and that the loss of bearing capacity is due to the initial axial forces. The whole procedure being validated, the question of the stability of elastic grid shells can be addressed.

\section{STABILITY OF PSEUDO-FUNICULAR ELASTIC GRID SHELLS}

\subsection{Description of the problem}

The study is conducted on pseudo-funicular elastic grid shells. In other words, the geometries generated are the result of the deformation of flat grids subject to uniform vertical line loads. In the spirit of the first grid shells of Frei Otto, this choice will induce a good behavior of the structure under self-weight. This formfinding method also implies that the structure is globally under compression when braced, which is not the case of form-finding methods such as [23]. Due to symmetries that simplify the interpretation of the results, the topology chosen is a circular flat grid.
The independent parameters chosen to describe the problem are shown in Fig. 7:

- $\quad$ the rise of the grid shell $h$;

- $\quad$ the initial diameter of the grid $L$ (the final span $L$ ' depends on $L$ and $h$ );

- $\quad$ the spacing between elements $l$;

- $\quad$ the bending stiffness of the elements EI;

- the critical line load $P_{c r}$.

It is possible to create three non-dimensional numbers from these five dimensional parameters:

$$
\begin{aligned}
& \text { Curvature parameter: } \Pi_{1}=\frac{h}{L^{\prime}} \\
& \text { Mesh density parameter: } \Pi_{2}=\frac{l}{L} \\
& \text { Stiffness parameter: } \Pi_{3}=\frac{p_{c r} L^{3}}{E I}
\end{aligned}
$$

In this work, two mesh densities, or equivalently two values of $\Pi_{2}(1 / 8$ and $1 / 16)$ have been considered, whereas ten rise-over-span ratios, or equivalently values of $\Pi_{1}$ varying between $20 \%$ and $50 \%$ have been studied. The diameter of the grid has been set to $15 \mathrm{~m}$ and the beams are circular hollow section with an external diameter of $42 \mathrm{~mm}$, a thickness of $3 \mathrm{~mm}$, and a Young's Modulus of $25 \mathrm{GPa}$. This makes the grids studied comparable with the elastic grid shell presented in [4]. Finally, a last case with a diameter of $\mathrm{L}=45 \mathrm{~m}$ and $\Pi_{2}$ of $1 / 16$ has been added to the set of data in order to have more information on the behavior of elastic grid shells subject to local member buckling.

This study focuses on single layer grid shells, because the influence of the pre-stress is expected to be more significant. The stiffness of the unconnected grids is far lower than the final stiffness: the forces and moments due to pre-stress are therefore lower in double layer grids. Some studies on the stability of prebuckled arches made out of sandwich panels indicate that the pre-stress plays a very limited role [24].

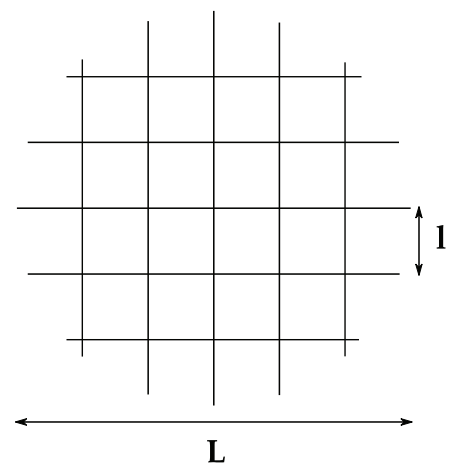

Plan view

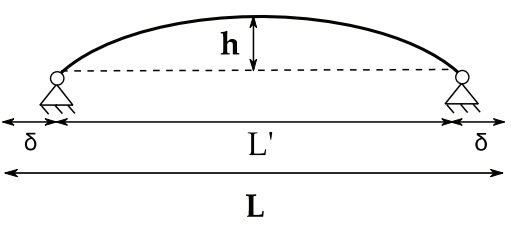

Side view

(simplified)

Figure 7. Description of the parameters. 


\subsection{Choice of the parameters space}

The choice of the range of parameters is based on a careful review of the major examples of existing elastic grid shells to this day. The geometrical and mechanical characteristics of these structures are recalled in the Table 3. The geometrical features of grid shells were taken from $[2,3,4,5,14,26]$ and are summed up in [18]. A more recent review of properties of elastic grid shells taking non-regular grid shells is presented in [14]. The review proposed in this paper and summed up in Table 2 considers two restrictions: the built elastic grid shell has to carry loads other than its self-weight, and must be constructed from a regular grid.

A Young's modulus of $10 \mathrm{GPa}$ was considered for timber, and a Young's modulus of $26.7 \mathrm{GPa}$ for GFRP was taken based on experimental studies of [4] and [27]. The inertia of the double-layered grid shells was calculated considering that the different layers were rigidly connected.

In practical cases, the parameter $\Pi_{1}$ varies between $30 \%$ and $58 \%$. The values superior to $50 \%$ occur for barrel vault geometries, but not for domes, due to the limitation of stresses in the members. The existing elastic grid shells can be considered as high-rise shells, and therefore act in axial forces. The authors choose here to add low-rise domes in the parametric study, so that elastic grid shells subject to bending modes are considered. Based on this review, the study space for parameter $\Pi_{1}$ has been chosen as follows:

$$
20 \%<\Pi_{1}<50 \%
$$

The value of $L^{3} / E L$ varies a lot between the first projects designed by Frei Otto with Ted Happold at Ove Arup and the more recent projects designed by Buro Happold. This parameter, which corresponds to the softness of the structure, has decreased significantly, probably due to the requirements of building codes. The
Earth Centre Grid Shell is a pavilion, built with different structural considerations compared to the other elastic grid shells. From this study follows therefore the range of values observed in existing projects, except the Earth Centre Grid Shell:

$$
0.1<\frac{L^{3}}{E I}<2
$$

Finally, the ratio $\prod_{2}=\frac{l}{L}$ varies between $1 \%$ and $18 \%$ in existing projects. The authors propose following variations for $\Pi_{2}$ :

$$
6 \%<\Pi_{2}<25 \%
$$

The exploration of the parameter space is inspired by the work of $[8,11]$ and is summed up in Fig. 8.

\subsection{Influence of the pre-stress on the mode shapes}

The analysis of the mode shapes demonstrates that the pre-stress does not influence the type of failure mechanism in the examples of the parametric study. Fig. 10 illustrates that the failure mechanisms encountered vary from local node snap-through to single member buckling or global buckling.

In the cases where $L=15 \mathrm{~m}$, the first mode is a global mode, whereas local modes can occur in the structures where $L=45 \mathrm{~m}$, due to a larger member length.

\subsection{Influence of the pre-stress on the bearing capacity of elastic grid shells}

It appears that, like in the $2 \mathrm{D}$ case, the pre-stressed structure has a lower bearing capacity than the rigid structure, as seen in Fig. 11. The relative loss of bearing capacity is however inferior to the one observed for the pre-buckled arches. The mean value of the ratio of

Table 2. Comparison of built elastic grid shells

\begin{tabular}{lcccccc}
\hline Name/Location & $\begin{array}{c}\text { Single/Double } \\
\text { Layer (SL/DL) }\end{array}$ & Year & $\begin{array}{c}\text { Cross Section } \\
{\left[\mathrm{mm}^{2}\right]}\end{array}$ & $\Pi_{1}$ & $\frac{L^{3}}{E I}\left[m m \cdot N^{-1}\right]$ & $\Pi_{2}$ \\
\hline Essen & $\mathrm{DL}$ & 1962 & $60 * 40$ & $30 \%$ & 1.51 & $2.9 \%$ \\
Mannheim & $\mathrm{DL}$ & 1975 & $50^{*} 50$ & $29 \%$ & 1.23 & $0.9 \%$ \\
Earth Centre & $\mathrm{SL}$ & 1998 & $32 * 15$ & $50 \%$ & 2.4 & $3.3 \%$ \\
Downland & $\mathrm{DL}$ & 2002 & $50 * 35$ & $58 \%$ & 0.1 & $6.0 \%$ \\
Savill & $\mathrm{DL}$ & 2006 & $80 * 50$ & $30 \%$ & 0.1 & $3.6 \%$ \\
GFRP Grid shell & $\mathrm{SL}$ & 2007 & $\mathrm{D}=42, \mathrm{t}=3$ & $57 \%$ & 0.19 & $18.2 \%$ \\
Solidays & $\mathrm{SL}$ & 2012 & $\mathrm{D}=42, \mathrm{t}=3$ & $47 \%$ & 0.09 & $14.2 \%$ \\
Créteil Cathedral & $\mathrm{SL}$ & 2013 & $\mathrm{D}=42, \mathrm{t}=3$ & $47 \%$ & 0.09 & $14.2 \%$ \\
\hline
\end{tabular}




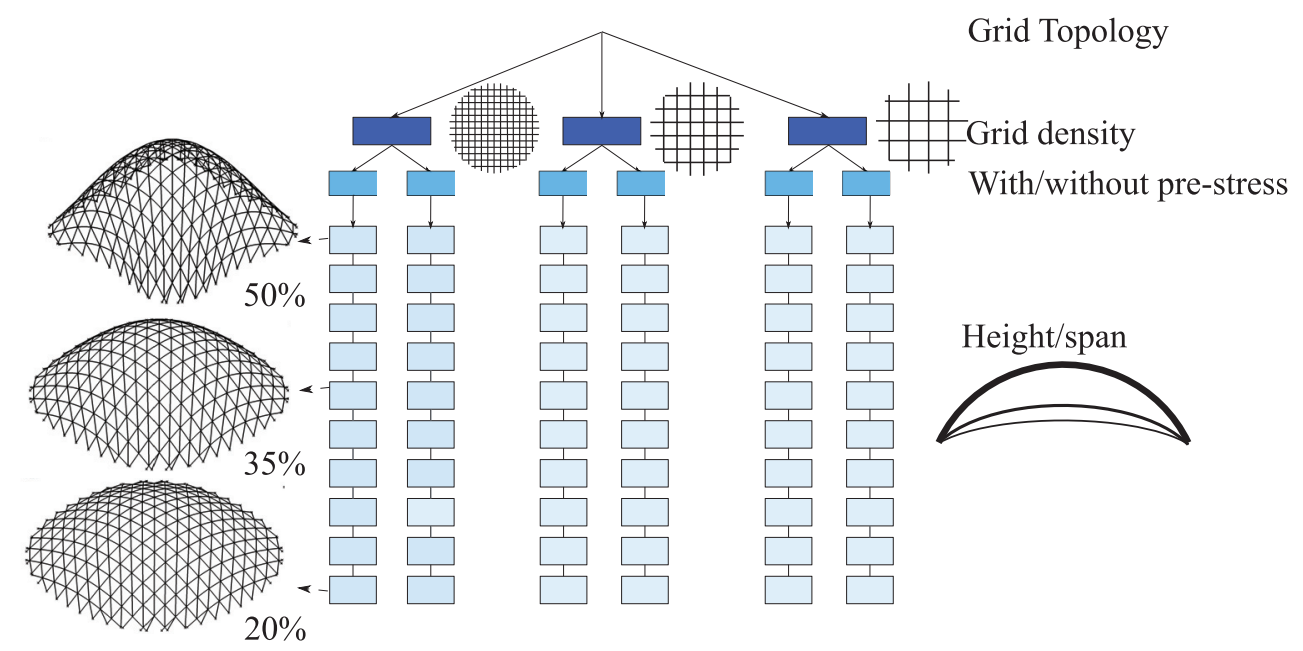

Figure 8. Methodology for the exploration of the parameter space.
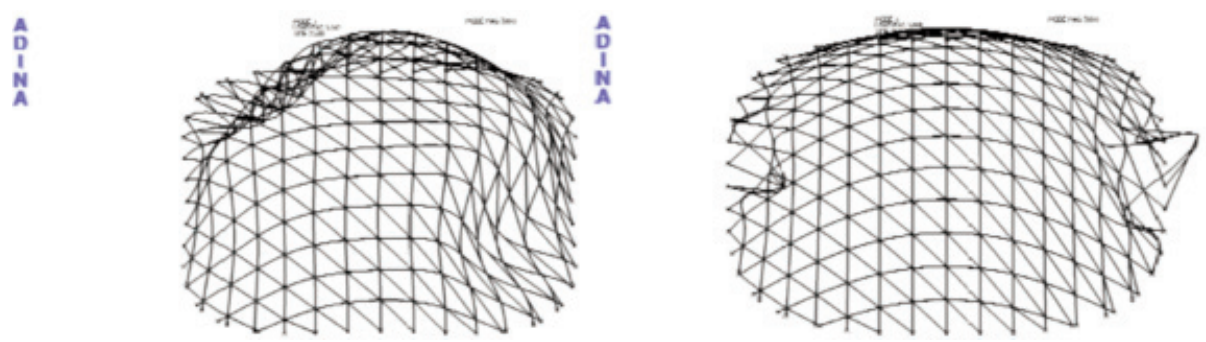

Figure 9. Mode shapes for two grids, $\Pi_{2}=1 / 16$ and $\mathrm{L}=15 \mathrm{~m}$ (left) and $\mathrm{L}=45 \mathrm{~m}$ (right).

the critical loads of pre-stressed and rigid structures for $\Pi_{2}=1 / 16, \Pi_{2}=1 / 8$, and $L=15 \mathrm{~m}$ is given by:

$$
\mathrm{r}_{\text {mean }}=\left.\frac{p_{c r, \text { pre-stressed }}}{p_{c r, \text { rigid }}}\right|_{\text {mean }}=94 \%
$$

This decrease is far less important than the one observed for pre-stressed arches, and can be considered as negligible compared to other effects (geometric or load imperfections). The pseudofunicular state induces compression forces destabilizing the structure, which implies that the ratio is necessarily inferior to 1 .

This difference between arches and grid shells illustrates the structural behavior of elastic grid shells. Once the bracing is introduced, the grid shell no longer acts as a network of arches. For the same level of prestress, the bracing introduces membrane-shear

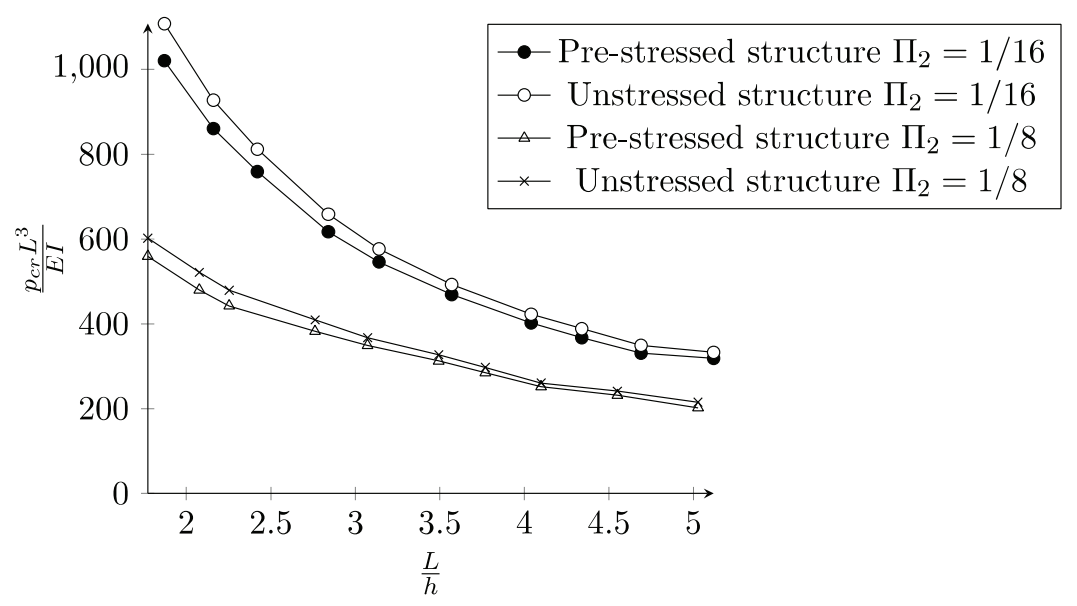

Figure 10. Non-dimensional critical line load for the two grids with $\mathrm{L}=15 \mathrm{~m}$. 
stiffness. This explains the decrease of the influence of the pre-stress on the buckling capacity of elastic grid shells compared to arches.

The only other case study on the buckling of elastic grid shells is presented in [23]. The magnitude of the influence of the pre-stress has been observed, with a change in buckling load limited to less than ten percent. Unlike the study in [23], the pre-stress systematically affects negatively the bearing capacity of elastic grid shells evaluated in this paper. The bracing technique introduced in this paper preserves the force field of the two-way grids. Since only pseudo-funicular shapes are considered, it consists mainly of compression forces. The third pre-stressed layer, and the addition of eccentricities between layers create a more complex force field in the structures studied in [23]. Indeed, tension force can appear and their stabilizing effect improves the bearing capacity of elastic grid shells. This is another illustration of the predominance of the importance of axial forces over bending forces when stability of active-bending structures is concerned.

\section{CONCLUSION}

In this paper an analysis method for structures deriving their stiffness from pre-stress, more specifically prebuckled arches and elastic grid shells, has been proposed. Main contributions include:

- Analysis procedure for pre-stressed structures;

- Analytical solutions for the shallow pre-buckled arches;

- Review of built projects in terms of mechanical parameters;

- Creation of a set of data on the buckling of elastic grid shells.

The set of data created shows that the pre-stress does not influence the mode shapes for reasonably sized grid shells. These different contributions lead to a simplified estimation of the buckling capacity of elastic grid shells subject to funicular loading, provided that the buckling mode is a shell mode. The influence of initial axial forces over bending moments is highlighted: the study illustrates the destabilizing effect of compression forces in pre-stressed structures. This effect is important for pre-stressed arches, but remains limited for elastic grid shells. This paper focuses on single layer grid shells, double layer grid shells are expected to be less affected by pre-stress. Indeed, beams have a high flexibility before the two layers are connected for composite action, meaning that the overall pre-stress and moment are lower in double layer grid shells.

Further work could include the study of nonfunicular loading as well as full non-linear calculations to determine the influence of imperfections. A linear buckling analysis, like the one performed in this paper, is indeed suitable for early stages of design, but the final design requires a full nonlinear analysis with imperfections. This work demonstrates that the buckling analysis of elastic grid shells can in many ways be related to the one of rigid grid shells. Therefore, all the progress made in the optimization of rigid grid shells could be transposed to elastic grid shells.

\section{REFERENCES}

[1] Knippers, J. and Helbig, T. Recent Developments in the design of Glazed Grid Shells, International Journal of Space Structures, Vol. 24, No. 2, (2009).

[2] Happold, E. and Liddell, W.I. Timber Lattice Roof for the Mannheim Bundesgartenschau, The Structural Engineer, Vol. 53, (1975), pp. 99-135.

[3] Harris, R., Romer, R., Kelly, O. and Johnson, S., Design and Construction of the Downland Gridshell, Building Research and Information, Vol. 31, No. 6, (2003), pp. 427-454.

[4] Douthe, C., Baverel, O. and Caron, J.-F. Form-Finding of Grid Shell in Composite Materials, International Journal of the International Association for Shell and Spatial Structures, Vol. 47. No. 150.

[5] Du Peloux, L., Tayeb, F., Baverel, O., Caron, J.-F. Faith can Also Move Composite Gridshells, IASS Symposium 'Beyond the Limits of Man' (2013).

[6] Bulenda, Th. and Knippers, J. Stability of Grid Shells, Computers and Structures, Vol. 79, No. 12, (2001), pp. 1161-1174.

[7] Timoshenko, S.P and Gere, J.M. Theory of Elasticity, Dover Civil and Mechanical Engineering Series, Dover Publications (2009).

[8] Kato, S., Fujimoto, M., and Toshiyuki, O. Buckling load of steel single-layer reticulated domes of circular plan, Journal of the International Association for Shell and Spatial structures, Vol. 46, No. 147, 2005, pp. 41-63.

[9] Malek, S., The effect of geometry and topology on the mechanics grid shells, Doctoral dissertation, Massachusetts Institute of Technology, (2012).

[10] DIN 18800, Stahlbauten: Bemessung und Konstruktion, part 2, (1990).

[11] Eurocode 3, Appendix C: Finite Element Method of Analysis (2006).

[12] Malek, S., Wierzbicki, T. and Ochsendorf, J. Buckling of spherical cap gridshells: A numerical and analytical study revisiting the concept of equivalent continuum, Engineering Structures, Vol. 75, (2014), pp. 288-298.

[13] Bouhaya, L., Baverel, O. and Caron, J. F. Mapping twoway continuous elastic grid on an imposed surface: Application to grid shells. In Symposium of the International Association for Shell and Spatial Structures (2009. Valencia).

[14] Quinn, G. Gengnagel, C. A review of elastic grid shells, their erection methods and the potential use of pneumatic formwork, in 4th International Conference on Mobile, Adaptable and Rapidly Assembled Structures MARAS2014, At Ostend, Vol. 136 (2014).

[15] ADINA Theory and Modelling Guide, Vol. 1-3. ADINA R\&D Inc.; (2003). 
[16] Chini, S. and Wolde-Tinsae, A. Buckling Test of Prestressed Arches in Centrifuge, J. Eng. Mech., 114(6), (1988), pp. 1063-1075.

[17] Seyed, S. and Wolde-Tinsae, A. Effect of prestressing on elastica arches. Journal of Engineering Mechanics, Vol. 114, No. 10, (1988), pp. 1791-1800.

[18] Thompson, J.M.T. and Hunt, G.W. On the buckling and imperfection sensitivity of arches with and without pre-stress, International Journal of Solids and Structures, Vol. 19, No. 5, (1983), pp. 445-459.

[19] Mesnil, R., Stability of Elastic Grid Shells, MIT Master Thesis, (2013).

[20] Bathe, K.-J., Finite Element Procedures, (2006).

[21] Mesnil, R., Ochsendorf, J. and Douthe, C. Influence on the pre-stress on the stability of elastic grid shells, IASS Symposium 'Beyond the Limits of Man', (2013).

[22] Pone, S. et al., Timber Post-Formed Gridshell: Digital Form-finding/Drawing and Building Tool, IASS Symposium 'Beyond the Limits of Man', (2013).
[23] Lefevre, B., Douthe, C. and Baverel, O. Buckling of elastic gridshells, accepted for publication in the Journal of the International Association of Shell and Spatial Structures, (2015).

[24] Mirmiran, A. and Wolde-Tinsae, A.M. Stability of prebuckled sandwich elastic arches: parametric study, Journal of Engineering Mechanics, Vol. 119, No. 4, (1993), 767-785.

[25] Douthe, C., Baverel, O. and Caron, J.-F., Gridshell structures in glass fibre reinforced polymers, Construction and Building Materials, Vol. 24, No. 9 (2010), 1580-1589.

[26] Baverel, O., Caron, J.F., Tayeb, F. and Du Peloux, L., Gridshells in composite materials : Construction of a $300 \mathrm{~m}^{2}$ Forum for the Solidays' Festival in Paris, Vol. 22, No. 3 (2012), 408-414.

[27] Kotelnikova-Weiler, N., Douthe, C., Lafuente Hernandez E., Baverel, O., Gengnagel, C. and Caron, J.-F., Materials for Actively Bent Structures, International Journal of Space Structures, Vol. 22, No. 3-4, (2013), 229-240. 